15. Михелькевич В.Н., Овчинникова Л.П. Учебный модуль-конструкт самоуправляемой дидактической системы формирования предметных компетенций // Вестник Самарского государственного технического университета. Серия Психолого-педагогические науки. 2011. № 1 (15). С. 83-88.

16. Капица П.Л. Эксперимент, теория, практика. М.: Изд-во «Наука», 1977. 351 с.

17. Кравцов П.Г., Михелькевич В.Н. Метод и средства измерения уровней сформированности функционально-профессиональных компетенций у выпускников технических вузов // Вестник Самарского государственного технического университета. Серия
«Психолого-педагогические науки». 2010. № 6 (14).

C. $125-130$

18. Коверялг А.А. Методы исследования в профессиональной педагогике. Вильнюс: Изд-во Валгус, 1980. 334 c.

19. Гуменникова Ю.В., Рябинова Е.Н., Черницына Р.Н. Статистическая обработка результатов тестирования студентов // Вестник Самарского государственного технического университета. Серия «Психолого-педагогические науки». 2015. № 3(27). С. 78-87.

20. Новиков Д.А. Статистические методы в педагогических исследованиях. М.: МЗ-Пресс, 2004. 67 с.

\title{
SYSTEM FORMATION MODEL OF STUDENTS' EXPERIMENTAL AND RESEARCH COMPETENCE
}

(C) 2016

\section{D.V. Popov, senior lecturer of the Chair of General Physics and Physics of Oil and Gas Production Samara State Technical University, Samara (Russia)}

Abstract. The article presents the research results of the formation model of students' professional experimental and research competences during performance of laboratory and experimental works. It explains the problem and solution of professional training of specialists in physical processes of oil and gas industry. It shows the meaning of laboratory and experimental works in competence paradigm of specialists in physical processes of oil and gas industry.

Here author represents such concept as «professional experimental and research competence» and defines its functionality and content components.

It points out the formation model of students' professional experimental and research competences during performance of laboratory and experimental works which is an algorithm and system navigator for developers and users of similar systems.

The author notes descriptors of functionality and content components which use such as criterion of the formation level of students' professional experimental and research competence.

The article points out the structure and content of the information and didactic basis based on the laboratory works complex in physical processes of oil and gas industry.

The article represents the results of ascertaining and forming experiment. It determines the initial and final equation of formation in experimental and control groups. It shows the feasibility and effectiveness of using high innovative competence modular technology of laboratory and experimental works.

Keywords: professional experimental and research competence; laboratory and physical experiment; oil and gas industry; system formation of professional competence; competence modular technology; information and didactic basis; laboratory and experimental work; criterion of the formation level.

УДК 378

\section{ФОРМИРОВАНИЕ НОРМ ПРОФЕССИОНАЛЬНОГО ПОВЕДЕНИЯ БУДУЩИХ ПЕРЕВОДЧИКОВ НА ЗАНЯТИИ-ПРОФИССЛЕДОВАНИИ В СИСТЕМЕ ВЫСШЕГО ОБРАЗОВАНИЯ}

(C) 2016

\author{
А.Н. Рыблова, доктор педагогических наук, профессор, \\ профессор кафедры лингвистики и межкультурной коммуникации \\ Российский новый университет, Москва (Россия)
}

\begin{abstract}
Аннотация. В статье поставлена актуальная проблема повышения качества практической подготовки кадров международного уровня, для решения которой автор предлагает формировать нормы профессионального поведения на занятии-профисследовании в системе высшего образования. На основе теоретико-методологического анализа работ отечественных и зарубежных ученых автор статьи предлагает модернизировать технологию организационного процесса исходя из запросов работодателей и индивидуальных потребностей обучающихся. При этом основным видом деятельности обучающихся на занятии-исследовании должна стать самостоятельная познавательная деятельность, ориентированная на их будущую профессию, для реализации которой в статье предлагается подробное описание различных видов групповой деятельности обучающихся, направленных на переработку иноязычной профессионально значимой информации в профессионально заданных ситуациях под руководством преподавателя. Опираясь на многолетний опыт педагогической деятельности в вузе, автор подтверждает, что такой вид занятия содействует приобретению обучающимися опыта профессиональной деятельности, формированию организационных и производственных навыков, обеспечива-
\end{abstract}


ет их личностный рост, что, в конечном счете, способствует интенсивной и качественной практической подготовке переводчиков в системе высшего образования.

Ключевые слова: нормы профессионального поведения; будущие переводчики; занятие-профисследование; система высшего образования; практическая подготовка кадров; профессионалы международного уровня; самостоятельная познавательная деятельность; ориентация на будущую профессию; модернизация технологии организационного процесса; групповые виды деятельности; иноязычная профессионально значимая информация; профессионально заданные ситуации; под руководством преподавателя; приобретение опыта; запросы работодателей; индивидуальные потребности обучающихся; формирование организационных и производственных навыков; обеспечение личностного роста.

В современных социально-экономических условиях в России необходима подготовка профессионалов международного уровня, свободно владеющими 1-2 иностранными языками и способными самостоятельно без посторонней помощи осуществлять межкультурную профессиональную коммуникацию. Такие профессионалы должны владеть научными, технологическими, менеджериальными знаниями и умениями, профессиональными навыками, позволяющими самостоятельно и быстро адаптироваться в непрерывно меняющейся информационной и технологической среде [1]. При этом важно, чтобы еще в вузе осуществлялась подготовка студентов к самостоятельному пополнению знаний и приобретению умений и навыков по избранной специальности, самоуправлению своим поведением. Для этого требуется пересмотр концептуальных основ организации и руководства самостоятельной познавательной деятельностью (СПД) студентов вуза в плане ее ориентации на их будущую профессию $[2 ; 3 ; 4 ; 5 ; 6]$. От жесткого, авторитарного управления, когда студент выступает «объектом» обучающих воздействий, происходит переход к системе организации поддержки и стимулирования познавательной самостоятельности субъекта образовательного процесса, созданию условий для реализации его профессиональных потребностей. Это предполагает повышение уровня личностной активности студентов вуза и преподавателей, превращает обучение в процесс межличностного взаимодействия и общения $[7 ; 8]$. Он организуется для достижения объединяющей их цели - формирования норм профессионального поведения у студентов вуза, обеспечивающих переход обучения в самообучение, управления - в самоуправление [9].

Инновационный подход к решению исследуемой проблемы обусловлен социальными запросами нашего времени, когда нынешний и будущий россиянин должен иметь высокий уровень общеобразовательной подготовки и обладать способностью и профессиональными навыками принимать самостоятельные решения [10]. Для его реализации в высшей школе осуществляется переход на уровневую систему подготовки кадров, осваиваются новые образовательные стандарты. Но этого недостаточно. Необходима модернизация технологии организационного процесса в вузе, его методов, форм и средств $[11 ; 12 ; 13]$. Это вызвано тем, что парадигма деятельности нашей высшей школы долгое время была сориентирована на подготовку специалистов, обладающих большим объемом фундаментальных знаний, но не умеющих их адекватно интерпретировать и, как следствие этого, медленно адаптирующихся к быстро меняющимся условиям в сфере их профессиональной деятельности [1]. Они нередко оказываются беспомощными там, где требуются самостоятельность и компетентность в принятии решений, умение организовать свою работу и деятельность других в обстановке большой неопределенности и повышенного риска. Между тем, современный этап развития нашей страны требует специалистов с широким гуманитарным мышлением, способных строить профессиональную деятельность по законам постиндустриального развития, учитывающих органическую связь между экономической продуктивностью и творчеством, с одной стороны, и стремлением человека к личной самореализации - с другой $[7 ; 8 ; 14]$.

Общеизвестно, что современная система лингвистической подготовки специалистов разных профилей не всегда обеспечивает формирование умений и навыков иноязычной профессиональной коммуникации. В связи с этим существует насущная потребность в компетентных переводчиках, способных выступать посредниками в межязыковом профессиональном общении. Однако по сравнению с теоретической подготовкой, существует проблема совершенствования практической профессиональной подготовке переводчиков.

Для решения проблемы интенсивного и качественного формирования норм профессионального поведения будущих специалистов в современной образовательной организации высшего образования необходимо, на наш взгляд, модернизировать технологию организации самостоятельной познавательной деятельности обучающихся в аудиторное время под руководством преподавателя [13; 15]. Теоретико-методологический анализ различных подходов к проблеме организации и руководства самостоятельной познавательной деятельностью студентов, а также современные социально-экономические условия и тенденции развития высшего лингвистического образования диктуют насущную необходимость ее ориентации на будущую профессию выпускника. Он показал что, преподаватели должны четко представлять себе роль, место и возможные сферы применения знаний той или иной дисциплины в жизни и профессиональной деятельности будущего выпускника и формировать во время аудиторных занятий нормы поведения, которые будут востребованы в его профессиональной деятельности, создадут ему перспективы для продвижений и успеха $[1 ; 2 ; 3 ; 4 ; 5]$.

Нормы профессионального поведения мы определяем как эталон профессиональной деятельности, представляющий собой совокупность профессиональных действий (выполняемых специалистом в соответствии с критериями, определяемыми определенной профессией) и этических правил профессиональной коммуникации для интенсивного и качественного достижения профессионально значимых целей. Для 
овладения нормами профессионального поведения в образовательной организации высшего образования необходима, прежде всего, целенаправленная интенсивная (6-8 часов в неделю) организация аудиторных практических занятий, проводимых в профессионально заданных ситуациях и моделирующих реальные условия будущей профессии студентов. Мы называем такие практические «занятия-профисследования» $[4 ; 5 ; 6]$. Они специально организуются преподавателем и обеспечивают обучающимся условия для активной групповой и индивидуальной переработки иноязычной профессионально значимой информации, апробации и тренировки их профессиональных действий, освоения правил этических профессиональных внутригрупповых и межгрупповых взаимодействий.

Основная часть занятия-профисследования - это активная групповая и индивидуальная самостоятельная познавательная и исследовательская деятельность с различными видами источников иноязычной профессионально значимой информации в профессионально заданных ситуациях для достижения профессионально значимых целей под общим руководством преподавателя. Она предусматривает анализ информации, изученной на лекции и семинаре, и синтез новой информации, самостоятельно составленной в виде сообщения, доклада, презентации и т.п. и представленной для группового обсуждения, контроля и оценки ее качества $[4 ; 5 ; 15]$.

Занятие-профисследование на младиих $(1,2)$ курcax профессиональной подготовки переводчиков в вузе целесообразно проводить в группах по 5-7 человек, используя индивидуальные и групповые формы деятельности. При работе такими группами продолжительность занятия и право выбора иноязычной профессионально значимой информации остается за обучающимися в зависимости от профессионально заданных целей, создается свободная неформальная атмосфера, налаживается их взаимодействие, благодаря применению различных методов и средств организации самостоятельной познавательной деятельности. Группы создаются в соответствии с различными критериями: по длительности работы - кратковременные (не более 15 минут) группы и долговременные (30-60 минут) группы; по функциям - «проблемные группы», «групповая терапия», «жужжащие» группы, «мозговой штурм», «аквариум» [16; 17].

Проведение занятия-профисследования в форме «проблемных групn» позволяет обучающимся самостоятельно ставить и разрешить профессионально значимые проблемы, полностью раскрепоститься и высказать свои точки зрения, отличные друг от друга. Большое значение при этом имеет уровень языковой подготовки будущих переводчиков, их индивидуальные и личностные качества, заинтересованность в создании условий для свободного общения в рамках группового взаимодействия. Смысл заключается в том, чтобы обучающиеся привыкали работать в команде, распределять обязанности, поддерживать друг друга так, как это происходит в реальной профессиональной среде. Таких малых групп (подгрупп) может быть 2-3 в рамках одной большой группы. В зависимости от уровня языковой подготовки в каждой проблемной подгруппе предлагается для обсуждения и разрешения одна и та же проблема, но в разных ас- пектах: в теоретическом, экспериментальном, прикладном и др. или разные проблемы.

Организация «групповой терапии» на занятиипрофисследовании реализуется за счет имитации профессиональной проблемной ситуации, предлагаемой преподавателем или самими обучающимися. Например, для будущего переводчика это могут быть ситуации выбора тех или иных стратегий перевода (последовательного, синхронного, двустороннего и др.) и тактики профессиональных контактов с автором иноязычного текста, слушателем или читателем. Для разрешения подобных профессионально заданных ситуаций распределяются профессиональные роли и воспроизводятся реальные профессиональные действия и условия их реализации с последующим подробным анализом предложенных вариантов. При этом акцент делается на соблюдении обучающимися норм профессионального поведения: объеме, скорости, качестве иноязычной речевой деятельности, этике межличностного общения и взаимодействия, индивидуально-психологических особенностях переводчика, авторов иноязычных текстов, аудитории слушателей или читателей и т.п., развитии профессионально значимых качеств личности. Нужно отметить, что «групповая терапия» предполагает ведущую роль преподавателя, поэтому ее рекомендуется использовать на репродуктивно-поисковом уровне самостоятельной познавательной деятельности, ориентированной на будущую профессию обучающихся [2; $3 ; 4 ; 5]$.

Занятие-профисследование в форме «жужжащиих груnn, состоящих из 3-5 человек, предусматривают распределение учебной группы студентов на несколько (2-3) подгрупп. Каждая из групп получает одни и те же или разные профессиональные задания/ задачи и условия/ обстоятельства для их выполнения, вызывающие затруднения в реальной профессиональной деятельности переводчика. Для их решения предоставляется время, по истечении которого каждая группа докладывает о результатах профисследования в форме сообщения, группового интервью, презентации/демонстрации возможных вариантов профессионального поведения. Работа «жужжащих» групn завершается в процессе совместного обсуждения полученных результатов. Группы прекращают свою работу, если совместно найдено оптимальное решение. В процессе самостоятельной познавательной деятельности в таких группах, как правило, выявляются интеллектуальные и организационные лидеры. Кроме того, каждый обучающийся осознает, какова его роль в профессиональной команде (лидер, подчиненный), и для какого вида профессиональной деятельности (письменный, устный, синхронный перевод) он пригоден больше всего.

Проведение занятия-профисследования в форме «мозгового штурма», предназначено, прежде всего, для выдвижения за короткий промежуток времени большого количества гипотез решения заданной профессионально важной проблемы. «Мозговой штурм» проводится при участии всей учебной группы, перед которой ставится единая профессионально значимая задача предположить, к примеру, возможные варианты ситуаций и обстоятельств реализации профессиональных действий переводчика в условиях большой 
неопределенности и риска. При этом следует особо подчеркнуть, что познавательная задача должна быть относительно несложной, чтобы обучающиеся смогли выдвинуть не только много гипотез, но и вариантов их решения, провести анализ и оценку качества каждого из них. В противном случае этот вид групповой самостоятельной познавательной деятельности не приведет к получению запланированных преподавателем результатов и достижению профессионально заданных целей. Чем больше гипотез и путей их решения предложит будущий переводчик в образовательном процессе в вузе, тем более интенсивно и качественно он сможет реализовать приобретенные профессиональные знания и умения в реальной профессиональной деятельности. Проведение занятияпрофисследования в форме «мозгового штурма» активизирует мыслительную активность обучающихся, заставляет их задуматься о том, что в зависимости от разных жизненных обстоятельств и профессиональных условий существуют разные подходы к осуществлению профессиональных действий. Однако этическая сторона переводческой деятельности должна остаться неизменной. Можно рекомендовать «мозговой штурм» для проведения занятия-профисследования на поисково-исследовательском уровне самостоятельной познавательной деятельности, ориентированной на будущую профессию обучающихся [2; 3; 4; 5$]$.

Занятие-профисследование в форме «аквариума» предполагает разделение группы на подгруппы (А, В, C) по 3-5 студентов. Участники рассаживаются таким образом, что образуют три круга один в другом: группа А образует первый (внутренний), группа В средний, группа С - внешний круг. Члены группы А (мыслители) получают задание - решить профессионально значимую проблему в определенной профессионально заданной ситуации для достижения реальных профессиональных целей, обучающиеся начинают обсуждение и поиск ее решения. Члены группы В (оппоненты) наблюдают за процессом обсуждения и принятием решений в группе $\mathrm{B}$, делают соответствующие записи, сравнивают предложенный вариант со своим, хотя это не их прямая задача. Члены группы C (контролеры) фиксируют процесс и результаты деятельности групп А и В.

После 15-20-минутной групповой работы преподаватель предоставляет время для межгруппового обсуждения. В это время члены группы С вместе с преподавателем анализируют действия первых двух групп. Они определяют лидера группы А, отмечают степень слаженности совместной работы группы, оценивают качество групповой самостоятельной познавательной деятельности и полученных результатов. Затем преподаватель при участии студентов подводит итоги. Результаты аудиторной групповой работы обучающиеся оформляют в письменной форме во время внеаудиторной профессионально ориентированной самостоятельной познавательной деятельности и предъявляют их преподавателю для контроля и оценки. На следующем занятии по той же или уже другой теме обучающиеся меняются местами: группа А становится группой C, В - группой $\mathrm{A}, \mathrm{C}$ - группой В. Рассматривается проблема таким же образом, как и в первом случае. Наконец, на третьем занятии проводится последняя перемена мест: группа А становится группой $\mathrm{B}$; группа В - группой C; группа C - группой A.
Итоговое занятие-профисследование посвящается анализу проделанной работы, когда все участники, побывав в каждой из групп, могут обобщить работу совместно с преподавателем или без его прямого участия. Форма групповой деятельности «аквариум» на занятии-профисследовании подчеркивает, таким образом, важность «прозрачности» профессиональной деятельности переводчика, открытой для наблюдения, критики и контроля. Кроме того, она готовит будущего переводчика к выполнению разных профессиональных функций, начиная с исполнительских действий и завершая менеджериальными обязанностями по контролю и оценке. Таким образом, описанные выше формы групповой деятельности студентов младших курсов на занятии-профисследовании можно также рекомендовать для поисково-исследовательского уровня самостоятельной познавательной деятельности, ориентированной на будущую профессию обучающихся $[2 ; 3 ; 4 ; 5]$.

Занятие-профисследование на стариих (3-5) курcax профессиональной подготовки переводчиков в вузе рекомендуем проводить в группах, включающих 10-15 обучающихся. При этом можно выделить такие формы, как «круглый стол», коллоквиум, симпозиум/форум $[16 ; 17 ; 18]$.

Проведение занятия-профисследования в форме «круглого стола» предусматривает полилог - обсуждение всей группой студентов профессионально значимых прикладных проблем, например, проектирование стратегии и тактики того или иного вида перевода; подбор оптимальных языковых средств (грамматических структур, стилистических приемов и т.п.) с целью достижения адекватности перевода; специфика перевода текстов с разным по профилю содержанием (напр. художественный, экономический, политический, военный и др.); возможности и условия взаимодействия субъекта и объекта переводческой деятельности в разных профессиональных ситуациях; критерии оценки качества перевода и профессиональной деятельности переводчика и т.п. Для эффективной организации такой формы групповой деятельности необходима большая предварительная подготовка самих обучающихся в плане содержания, алгоритма проведения, распределения обязанностей и т.п.

«Круглый стол» функционирует под общим руководством 1-2 преподавателей, которые наблюдают, но не вмешиваются в процесс аудиторной групповой и индивидуальной самостоятельной познавательной деятельности обучающихся, ориентированной на их будущую профессию. Мы видим цель такой в том, чтобы выявить и развить у обучающихся способность свободно и неординарно мыслить, грамотно высказывать и аргументировать свои взгляды, презентовать и корректно отстаивать собственную точку зрения, не испытывая при этом психологического дискомфорта и т.п. Кроме того, такая форма групповой деятельности предоставляет возможность будущим переводчикам научиться самоорганизовывать, саморегулировать и самоконтролировать профессионально заданную деятельность.

Коллоквиум имеет много общего с «круглым столом». Разница в том, что в рамках коллоквиума в большей мере осуществляется диалог двух лиц: студента и преподавателя, двух преподавателей, студен- 
та и группы и т.п. При этом другие члены группы наблюдают за диалогами, делают соответствующие записи и затем задают вопросы, на основе ответов на которые осуществляют взаимоконтроль и взаимооценку уровня усвоения сокурсниками иноязычной профессионально значимой информации, освоения норм профессионального поведения как результат самостоятельной познавательной деятельности, ориентированной на будущую профессию в аудиторное время.

Осуществление занятия-профисследования в форме симпозиума или форума, предполагает прослушивание или обсуждение иноязычной профессионально значимой информации, представленной 1-3 обучающимися в виде доклада/сообщения. Выступления студентов имитируют реальные выступления специалистов на научных и методических конференциях, симпозиумах и форумах и сопровождаются постановкой вопросов по темам выступления, которые постепенно переходят в групповое обсуждение важных профессиональных проблем студентами при участии 3-5 преподавателей.

«Симпозиум/форум» на занятии-профисследовании можно проводить в форме деловой игры, в рамках которой будущие переводчики смогут выполнить свои непосредственные профессиональные функции по устному двустороннему переводу докладов участников международного симпозиума/форума, включающего представителей разных стран, и продемонстрировать уровень овладения нормами профессионального поведения. В рамках занятий-профисследований в форме «симпозиума/форума» возможно также представление и обсуждение квалификационных работ студентов-выпускников для апробации их материалов и корректировки (при необходимости) основных положений и выводов проведенных профессионально значимых научных исследований. Таким образом, описанные выше формы групповой деятельности старших курсов (3-5) курсов на занятиипрофисследовании рекомендуем использовать для реализации на исследовательско-проектировочном уровне самостоятельной познавательной деятельности, ориентированной на будущую профессию обучающихся $[2 ; 3 ; 4 ; 5]$.

На основе нашего многолетнего (более 30 лет) опыта работы в вузе можем отметить, что успешность профессиональной деятельности переводчиков на занятии-профисследовании напрямую зависит от профессионализма преподавателя, от его умения творчески организовывать и руководить самостоятельной познавательной деятельностью обучающихся, ориентировать ее на их будущую профессию, варьировать различные методы, организационные формы и средства обучения, стимулируя, таким образом, само/взаимообучение, само/взимоконтроль и само/взаимооценку субъектов образовательного процесса.

Немаловажное значение при проведении занятияпрофисследования имеет актуальность и аутентичность содержания (иноязычной профессионально значимой информации). Для повышения качества практической подготовки будущих переводчиков на занятии-профисследовании преподаватели должны выявить запросы работодателей и индивидуальные потребности обучающихся о потенциальном будущем месте их профессиональной деятельности и разрабатывать рабочие программы, разные по содержанию и объему [1], и касающиеся различных профилей будущей профессиональной деятельности переводчиков. Это могут быть, например, программы обучения для работы в гостиничном и туристическом бизнесе, внешнеторговых компаниях, банках, в правоохранительных органах, на таможне и т.п. Кроме того, с учетом специфики профессиональной коммуникации будущих переводчиков необходимо научить алгоритму сопровождения международных встреч и дискуссий, осуществлению переговоров по телефону, описанию услуг той или иной компании и ее продукции, ведению иноязычной деловой переписки, оформлению документации, внешнеторговых контрактов и т.п. [13; 15].

Так как будущая профессиональная деятельность переводчиков будет связана с чтением и переводом большого количества документации, на занятиипрофисследовании уделяют много времени развитию навыков письма. Письменные работы чаще всего представляют собой изложения и сочинения-эссе, в которых обучающиеся должны изложить свои соображения на ту или иную тему, обосновать собственное мнение или логично изложить известные им факты, события, сделать выводы и т.п. Образовательный процесс, построенный таким образом, способствует будущим достижениям субъектов образования в профессиональной деятельности, так как современная профессиональная деятельность в большой степени связана с письменными иноязычными коммуникациями (электронная почта, смс-сообщения и др.).

Занятие-профисследование может быть направлено также на личностный рост будущего переводчика. Для этого преподаватели разрабатывают программы манипуляций и переговорных технологий, способов выработки уверенности, управления временем и людьми, искусства публичных выступлений и межкультурного общения. Субъектов образовательного процесса учат выступать перед аудиторией, осуществлять презентацию материалов и иллюстрировать выступление примерами. Однако показать знание материала, пересказав его без ошибки, - это еще не все. Обучающиеся должны продемонстрировать логически безупречную, убедительную речь, непременно содержащую собственную точку зрения. Кроме того, они должны произнести ее по всем правилам ораторского искусства: «с выражением», с риторическими фигурами, с подобающими жестами [18]. Если же выступающий студент не сможет убедить аудиторию в своей правоте, ему придется отвечать на многочисленные вопросы и принимать возражения. Поэтому обучающимся предлагают для образца прослушивать аудиоматериалы в исполнении носителей языка и показывают видеоматериалы успешно работающих специалистов-переводчиков. Задачи ставятся разные: успевать все делать вовремя, добиваться «своего» в споре с оппонентом и т.п.

Занятие-профисследование может быть направлено на формирование организационных и производственных навыков будущих переводчиков. Обучающихся учат проводить планерки, подбирать персонал, управлять своей деятельностью и деятельностью групп профессионалов и т.п. Это своего рода тренинги, на которых многократно тренируются профессио- 
нальные действия будущих специалистов в реальных профессиональных ситуациях [9]. Для достижения эффективности подобных тренингов преподавателю нужно изучить индивидуальные профессиональные потребности обучающихся, их ожидания и проблемы, и образовательный процесс строится с их учетом. При этом темп и стиль работы, последовательность и сложность заданий ориентируются на возрастные, гендерные и национальные особенности группы обучающихся, их уровень ЗУНов, индивидуально-психологические особенности и ценностные ориентации. На занятиях-профисследованиях, проводимых в форме тренингов, ряд преподавателей предпочитает использовать «case-study» (разбор конкретных ситуаций). В методической литературе [16;18] известны несколько типов «кейсов»:

- «структурированный кейс», содержащий минимум иноязычной профессионально значимой информации, для реализации которого применяют определенную модель, обеспечивающую принятие оптимального решения; его разбор можно рекомендовать 1-2 студентам;

- «маленькие наброски», включающие 1-10 страниц иноязычной профессионально значимой информации и 1-2 страницы терминов, способствующих интенсификации в усвоении ключевых понятий и переработки содержания; разбор такого кейса можно рекомендовать группе обучающихся в количестве 3-5 человек;

- «большие неструктурированные кейсы» объемом до 30-50 страниц иноязычной профессионально значимой информации, сложной по грамматической структуре и лексическому составу; разбор такого кейса можно рекомендовать группе обучающихся в количестве 15-25 человек;

Проведение занятия-профисследования в форме «case-study» вызывают у обучающихся много споров и сомнений, поэтому к образовательному процессу привлекают специалистов, имеющих опыт успешной переводческой деятельности с тем, чтобы они поделились удачными примерами. Это помогает обучающимся сразу после окончания образовательной организации настроиться на профессиональный лад и быстро «войти в профессию». В отличие от других организационных форм, такие занятия-профисследования проводятся в группах от 20 до 30 студентов с участием двух и более лекторов, так как это обеспечивает приобретение более разнообразного профессионального опыта.

Таким образом, самостоятельная познавательная деятельность обучающихся, ориентированная на их будущую профессию и организуемая на занятиипрофисследовании в аудиторное время под руководством преподавателя, способствует интенсивной и качественной практической подготовке переводчиков разных профилей, разбирающихся во многих ключевых проблемах современной межкультурной профессиональной коммуникации и успешно реализующих свои потребности во всех отраслях производства, бизнеса, политики, науки и культуры, как в России, так и за рубежом. Как показывает наш многолетний опыт теоретико-экспериментальной и практической педагогический деятельности, проведение занятийпрофисследований создает наилучшие условия для интенсивного и качественного формирования норм профессионального поведения будущих переводчиков в системе высшего образования.

\section{СПИСОК ЛИТЕРАТУРЫ:}

1. Рыблова А.Н. Разноуровневое управление профессиональной подготовкой и переподготовкой кадров в системе военного образования. М.: ВАГШ, 2015. $160 \mathrm{c}$.

2. Рыблова А.Н. Профессионально ориентированная самостоятельная познавательная деятельность: методологический анализ, разноуровневое управление. Саратов: Изд. центр СГСЭУ, 2010. 112 с.

3. Рыблова А.Н. Система управления профессионально ориентированной самостоятельной познавательной деятельностью студентов. Саратов: Изд. центр СГСЭУ, 2002. 200 с.

4. Рыблова А.Н. Управление самостоятельной познавательной деятельностью обучающихся в вузе. Саратов: Изд-во Сарат. гос. техн. ун-та, 1999. 144 с.

5. Рыблова А.Н. Самостоятельность студентов в профессионально ориентированном обучении иностранным языкам. Саратов: Изд. центр СГСЭУ, 2003. 72 с.

6. Рыблова А.Н. Система профессионально ориентированной самостоятельной познавательной деятельности // Совет ректоров. Специализированное профессиональное издание для вузов. М., 2010. № 3. C. 42-50. № 4. C. 41-42.

7. Globalization: a new paradigm for higher education // Higher education in Europe. 2001. Vol.XXV. № 1.

8. Memorandum on higher education in the European community. Brusel, 1991.

9. Рыблова А.Н. Управление образовательными системами. Саратов: Изд. центр СГСЭУ, 2009. 168 с.

10. Лобанов В.С., Иванников А.Д., Богатырь Б.Н. Концепция информатизации высшего образования в России // Высшее образование в России. 1994. № 1. C. 30 .

11. Рыблова А.Н. Технология управления образовательным процессом в системе непрерывного образования. Саратов: изд-во «Саратовский источник», 2009. 96 c.

12. Рыблова А.Н. Технология управления образовательным процессом студентов в университете. Саратов: Изд. центр СГСЭУ, 2006. 96 с.

13. Рыблова А.Н. Технологически организованная профессионально ориентированная самостоятельная познавательная деятельность студентов // Педагогическое образование и наука. 2014. № 4. С. 26-28.

14. Вуз и рынок: Конверсия, наука, образование. Кн. 3, 4 // Комитет по высшей школе. М., 1993.

15. Рыблова А.Н. Интенсивный цикл организационных форм обучения иностранным языкам в системе высшего образования // Цивилизация знаний: российские реалии. М.: РосНОУ, 2016.

16. Вербицкий А.А. Активное обучение в высшей школе: контекстный подход. М., 1991. 207 с.

17. Колесникова И.Л. и др. Англо-русский терминологический справочник по методике преподавания иностранных языков. СПб.: Изд-во «Русско-Балтийский информационный центр "БЛИЦ"», «Cambridge University Press», 2001. 224 c.

18. Диплом Гексагона // Образование за рубежом. Приложение «Европа». 2002. С. 120-123. 


\title{
FORMATION OF NORMS FOR THE FUTURE TRANSLATORS PROFESSIONAL BEHAVIOR AT THE PROFESSIONAL RESEARCH LESSON IN THE HIGHER EDUCATION SYSTEM
}

(C) 2016

A.N. Ryblova, doctor of pedagogical sciences, professor, professor of Linguistics and Intercultural Communication Department Russian New University, Moscow (Russia)

Abstract. The article touches upon an urgent problem to improve the quality of the personnel practical training, for which the author offers solutions to shape norms for future translators professional behavior at the professional research lesson in the higher education system. On the basis of theoretical and methodological analysis of the works of domestic and foreign scientists the author considers it necessary to modernize the technology of organizational process on the basis of needs of employers and individual needs of students. At the same time the main activity of students at the professional research lesson should be autonomous cognitive activity focused on their future profession, the realization of which the article offers a detailed description of different types of students' group activities aimed at processing foreign language professionally significant information in professionally given situations under the supervision of a teacher at the professional research lesson. The author, based on many years of experience teaching activities in the university confirms that this type of lesson promotes the acquisition by students of professional experience, the formation of organizational and production skills and provides personal development training, which ultimately contributes to the intensive and high-quality practical training of translators in the system of higher education.

Keywords: norms of professional behavior; future translators; professional research lesson; higher education system; practical training; professionals of international level; autonomous cognitive activity; focus on the future profession; technology modernization of organizational process; types of group activity; foreign language professionally significant information; professionally given situations; under the teacher supervision; experience acquisition; needs of employers; individual needs of students; formation of organizational and production skills.

удК 37.015.3:17.023.6

\section{МОРАЛЬНО-ЭТИЧЕСКИЕ ПРИНЦИПЫ КАК ПРЕДМЕТ ПЕДАГОГИЧЕСКОЙ РЕФЛЕКСИИ}

(C) 2016
А.И. Салов, кандидат педагогических наук, доцент, ректор
Академия сочиального управления, Москва (Россия)

\begin{abstract}
Аннотация. В статье обосновывается, что морально-этические принципы ориентируют учителя на совместный с учащимися поиск смысла жизни, который проясняет им отношения с миром, жизненный мир педагога и учащихся, существует в их сознании в виде образа мира и регулирует их совместную деятельность в соответствии с логикой жизненной необходимости - Мир на Земле. Объясняется, что подлинная мораль считает человека и его жизнь высшими моральными ценностями, в которых формулируются морально-этические принципы, предписывающие выработку стратегии нравственной жизни; обосновывается, что от правильного понимания ценностей зависит нравственность человека, его поступки, взгляды, оценки, цели и мотивы деятельности и взаимодействия с миром и с людьми; делаются пояснения относительно категорий «добродетель», «благо», в терминах которых формулируются морально-этические принципы; приводятся значения категорий «добродетель» и «благо»; объясняется, почему добродетели научить нельзя, что добродетели не являются врожденным, а потому они воспитываются; показывается, что моральное, этическое знание необходимо человеку для того, чтобы стать добродетельным; указывается на важность различения жизни как таковой и жизни хорошей; обосновывается, что морально-этические принципы задают учителю исходную аксиому (во имя чего?) - во имя достижения цели - Мир на Земле, стратегию движения по избранному пути (каков путь?) - созидание добра для себя и для учащихся.

Ключевые слова: учитель; ученик; морально-этический принцип; добродетель; благо; идеал; ценность; добро; значение; мораль; нравственность; педагогическая рефлексия; поступок; взгляд; оценка; логика жизни; аксиома; стратегия; движение; осознание; нравственная жизнь.
\end{abstract}

Морально-этические принципы ориентируют учителя на совместный с учащимися поиск смысла жизни, который проясняет им отношения с миром, жизненный мир педагога и учащихся; существует в их сознании в виде образа мира, в форме смысловых структур; обеспечивает регуляцию их совместной деятельности в соответствии с логикой жизненной необходимости - Мир на Земле. Таким смыслом жизни и для учителя, и для учащихся, и для всех людей доброй воли в современной социально-нравственной ситуации являются добро и добродетель.

Морально-этические принципы, в терминологии Ю.А. Шрейдера, принципы этики являются «универсальными характеристиками ситуации морального выбора» $[1$, с. 26] и формулируются «в понятиях морального блага (как блага абсолютного) и моральной ценности» [1, с. 254]. 